\title{
Knowledge flows from public science to industrial technologies
}

\author{
Lili Wang ${ }^{1}$ (D) $\cdot$ Zexia $\mathrm{Li}^{2,3}$ \\ Published online: 7 June 2019 \\ (c) The Author(s) 2019
}

\begin{abstract}
Scientific research has been acknowledged as an important knowledge resource for developing technologies. However, little is known about the heterogeneous nature of scientific knowledge and the associated contribution to technological advancement. Using nano technology as a case study, this paper investigates what types of scientific research can help improve the quality of technologies. This study uses backward and forward citation analysis, extracted from the Derwent World Patents Index. Non-patent citations from each patent are further connected with records indexed in Web of Science, and the forward citations for the cited articles are collected. On the one hand, our results confirm that there is an important contribution from science to technology. High-quality academic research has significantly contributed to the development of high-quality patents. On the other hand, this study also reveals the heterogeneous pattern of patents citing scientific publications, depending on the organizational type, country, and knowledge origin. Compared to those in the U.S., patents developed by Chinese inventors tend to reply on more recent science but with a narrower scientific scope.
\end{abstract}

Keywords Knowledge transfer $\cdot$ Publications $\cdot$ Patents $\cdot$ Citations $\cdot$ Science-technology linkages $\cdot$ Nanotechnology

JEL Classification $\mathrm{o} 31 \cdot \mathrm{o} 32 \cdot \mathrm{o} 33$

\section{Introduction}

Knowledge is regarded as one of the most important factors driving industrial innovations and economic performance. In order to foster innovation activities, great efforts were made to capture the underlying mechanism of knowledge production (Griliches 1979; Audretsch

Lili Wang

wang@merit.unu.edu

1 UNU-MERIT, Maastricht University, Boschstraat 24, 6211 AX Maastricht, The Netherlands

2 National Science Library, Chinese Academy of Sciences, Beijing, People's Republic of China

3 Department of Library, Information and Archives Management, School of Economics and Management, University of Chinese Academy of Sciences, Beijing, People's Republic of China 
and Feldman 1996; Zucker et al. 2007; Acs et al. 2002). Although R\&D investment and human capital have been widely used in measuring knowledge generation, it is acknowledged that it is not the physical input per se, but the knowledge associated with these inputs that matters for the generation of new knowledge (Griliches 1979). As stressed by Zucker et al. (2007), what matters is not the number of people working in this innovation agent but the knowledge, i.e. how these people master codified and tacit knowledge. Recent empirical studies also show that high physical R\&D investment does not necessarily generate a high knowledge output (Wang et al. 2019). In the knowledge-based economy, as pointed out by Audretsch and Link (2019), the competitive advantage of innovation agents has "shifted away from the traditional factor of physical capital toward knowledge" (Audretsch and Link 2019, p. 146).

The knowledge base covers a broad range of heterogeneous resources, hence a successful knowledge generation is based on the selection and integration of various existing knowledge (Audretsch and Link 2019). Towards understanding the mechanism of knowledge production and knowledge spillovers, Audretsch and Link (2019) stress the importance of knowledge contexts by stating that "recognizing the multidimensional nature of knowledge and ideas is another small step toward understanding" the various sources of knowledge and its impact on innovation (Audretsch and Link 2019, p. 40).

Given the various types, as emphasised in the literature (Fritsch 2002; Fritsch and Franke 2004), it is impossible to capture completely knowledge in practice. In this paper, we aim to dig into one type of knowledge contribution-scientific knowledge-and explore its associated characteristics in contributing to the development of industrial technologies. There are two reasons driving us to deepen our understanding of this type of knowledge. One is due to the long recognized importance of this knowledge stream. It is widely believed that scientific knowledge provides considerable contribution to the generation of new technological knowledge (Mansfield 1991; Narin et al. 1997; Branstetter 2005; Sorenson and Fleming 2004). The quality of technologies developed based on science is found to be significantly higher than that of non-science-based technologies (Sorenson and Fleming 2004; Malo and Geuna 2000; Wang and Li 2018). What's more, the integration of scientific knowledge to technologies is on the rise over time (Wang and Li 2018). This calls more attention than before to exploring the flows from scientific knowledge to technology. Another reason is that, despite the important role scientific knowledge plays in boosting technologies, it is acknowledge to be difficult to assess the connections between science and technology (Mansfield 1991).

By linking up the patent data (Derwent World Patents Index) with cited scientific publication data (Web of Science), this study aims to close this gap to explore the characteristics of scientific knowledge in contributing to the improvement of quality (or impact) of technologies. That is, to explore what types of scientific knowledge are more beneficial to help improve the patent quality (or impact). ${ }^{1}$ We focus on a series of scientific characteristics, including quality, newness, scope and country of origin of scientific research.

The rest of the paper is organized as follows. Section 2 provides the theoretical background and our research hypotheses. Section 3 explains the data collection and methodology of this paper. Section 4 documents the results of the analysis and Sect. 5 concludes.

\footnotetext{
1 Not all patents are useful, and some do not add knowledge value to the society or to other sequent technological development (Hoekman et al. 2009). Therefore, this study focuses on the patent quality rather than the quantity.
} 


\section{Theoretical framework and research hypotheses}

\subsection{Complexity of knowledge}

Knowledge is not only an output, but also an input (Antonelli 2007; Autant-Bernard et al. 2013). The generation of new knowledge depends on both internal and external knowledge input. Among the three input variables in the well-known knowledge production function (R\&D investment, human capital, and spillovers), the first two present the level/stock of internal knowledge, and the third one denotes the external knowledge (Griliches 1979; Grossman and Helpman 1990; Branstetter 2001). For innovation agents where the level of physical capital and human capital is limited, innovation performance crucially depends on whether they can utilize the existing external knowledge. This explains why some small and new firms, without much physical investment, are able to innovate (Audretsch and Link 2019; Acs et al. 1994). Developing countries can potentially benefit from the knowledge created from the advanced countries (Grossman and Helpman 1990). Leveraging knowledge spillovers from other advanced counterparts can be a more efficient way than directly investing (Wang et al. 2019).

Accumulated knowledge from both inside and outside is the core for innovation, however, as explained by Fritsch (2002), knowledge is always measured incompletely in empirical studies. This is greatly due to the heterogeneous nature of knowledge types and disparate knowledge sources (Audretsch and Link 2019).

Knowledge has both tacit and codified types. ${ }^{2}$ The former type is less articulated and often transferred via face-to-face interaction, in which case successful knowledge transfer replies on the physical distance between knowledge sources and recipients. However, the latter knowledge type can be stored in documents and hence transferred over long distances, and the dissemination of codified knowledge is less constrained by geographical locations (Audretsch and Feldman 2004; Feldman 1999). In this study, we will focus on the knowledge codified as scientific articles or patents, a type of knowledge spillovers that is less geographically bounded and can be traced by citations (Jaffe and Trajtenberg 2002).

Patents have been approved to be a reliable measure for innovation studies (Acs et al. 2002). The availability of reference lists provided by patents opens a window of opportunity to trace the knowledge sources contributing to the development of technologies (Jaffe and Trajtenberg 1996; Henderson et al. 1998). Given that access to scientific publications is approved to the be most important channel for knowledge transfer from public research to industry (Bekkers and Bodas Freitas 2008), this study focuses on scientific knowledge (i.e. journal publications) cited by patents and explores the related characteristics. Forward citations received by one patent are often used to indicate the importance and usefulness of this patent for the development of future technologies (Jaffe and Trajtenberg 2002; Keij1 et al. 2016; Henderson et al. 1998). In this paper, we aim to explore what types of scientific knowledge can help increase the impact (proxied by forward citations) of patents in the field of nano technology. The characteristics this study attempts to cover include quality of scientific knowledge, age of scientific results, scope and variety of knowledge, and knowledge origins.

\footnotetext{
${ }^{2}$ Knowledge and information are used to refer to tacit and codified ideas, respectively (see also in Audretsch and Link 2019, Chapter 2).
} 


\subsection{Quality of scientific knowledge}

The contribution of scientific knowledge to technology comes not only from the quantity (the amount) but also the quality (the usefulness) of cited science (Schartinger et al. 2002; Appio et al. 2017). In the existing literature, the quality of academic research is mainly represented by the evaluation indicators (i.e. ranking) of research departments. However, whether research from higher-quality research departments is really more beneficial to technological development is still a matter of debate. On the one hand, some scholars suggest that the contribution of science to industrial innovation is directly related to the quality (ranking) of the research departments where scientific research has been conducted (Mansfield 1995; Calcagnini et al. 2016). It is believed that more reputable research institutes are more likely to produce research that industry is looking for (Tornquist and Kallsen 1994). On the other hand, studies also show that the quality of a research department has no impact on the probability of S\&T interactions. Although the ranking of a research department is associated with the percentage of citations received by this institute (Mansfield 1995; Mansfield and Lee 1996), we argue that it is the quality of cited articles, rather than the quality of research institutes, contributing to the technological development. Hence, in this study we move a step further to investigate individual articles cited by patents. The cited articles are linked with information from Web of Science. We use the number of forward citations received by these articles as a proxy for the quality of cited science. By linking up the quality of cited publications with the quality of citing patents, we aim to test whether highly cited articles would help increase the impact (proxied by forward citations) of a citing patent.

We contend that the quality of cited papers matters in the development of technologies. Hence we develop the first hypothesis of this study as follows:

Hypothesis 1 Higher-quality science can lead to higher-quality patents.

\subsection{Age of scientific results}

Recent scientific publications represent the results of up-to-date academic research, hence timely knowledge flows are important to the success of enterprises and add more value to society (Nissen 2002; Liao and Phan 2016; Stephan 1996). However, it takes time for inventors to recognize and utilize scientific results, i.e. there is usually a time lag between the appearance of research output and its application to industry (Adams 1990; Mansfield 1991). Earlier studies attempted to test the time lag between patents and the cited academic articles. Popp (2017) finds that the probability of patents citing articles peaks 15 years after the article was published, while Finardi (2011) suggests that the time lag between production of scientific knowledge and its technological exploitation is about 3-4 years. As explained by Popp (2017), the time difference is likely caused by the sector-specific feature, for instance, energy research may take longer to progress to a commercialized product.

Besides the sector-specific feature, our study takes country-specificity and difference of knowledge origin into consideration. By controlling the country, organization, and knowledge origin variables, we expect that a timely knowledge transfer from science to technology is valuable for generating high-impact technologies. Hence we develop the second hypothesis as follows: 
Hypothesis 2 Recent scientific knowledge contributes most to patent quality.

\subsection{Scope and variety of knowledge}

In addition to the feature of scientific quality mentioned above, the quantity of cited articles is also one of the factors influencing the effect of knowledge transfers from science to technology. With the increasing trend of scientific application into technological development (Narin et al. 1997; Wang and Li 2018; Branstetter 2005), one may wonder whether more references to scientific articles would lead to a better quality patent. The existing literature show that diversified knowledge can lead to more innovation than specified knowledge does (Feldman and Audretsch 1999; Liao and Phan 2016). However, by looking at how science and technology are combined in one specific field, Appio et al. (2017) suggest that a high degree of knowledge diversity does not always lead to more impactful inventions.

We contend that the patterns of citation (in terms of how many scientific articles to cite or what kind of scientific articles to cite) are country-specific. In studying knowledge transfer, it is important to note the differences between countries of origin (Fernández-Ribas and Shapira 2009). Hence we develop the following hypothesis:

Hypothesis 3 Scientific references with a larger scope (or higher variety level) do not always have a higher contribution to patent quality.

\subsection{Knowledge origins}

Knowledge resources can be explored by studying the country of origin of references cited by industrial patents. Knowledge documented in an article is known as codified knowledge that can be easily circulated and exchanged. Different from tacit knowledge which is often socially localised, codified knowledge can be transferred easily over large distances (Cohendet and Meyer-Krahmer 2001). In theory, there is an equal chance for inventors to access and cite codified knowledge (e.g. scientific articles) from various geographical locations. However, studies also find that each country's inventions preferentially cite scientific articles from their own country (Narin et al. 1997), or even preferably from closely located institutes (Beise and Stahl 1999). This indicates that, to some extent, knowledge from home-country might be more relevant than that from foreign countries.

We tend to agree that there is a national bias in the citation patterns for industrial patents (Narin et al. 1997; McMillan et al. 2000). Although the existing studies have been limited to the developed countries, such as the U.S. and Japan, we expect there is also a national bias in the citing patterns in developing countries.

Hypothesis 4 There is a significant difference between country origins of knowledge in the process of producing impactful patents.

\section{Data collection and methodology}

Disciplinary origin is an important factor in influencing the pattern and intensity of knowledge transfer from science to technology (Wang and Li 2018; Bekkers and Bodas Freitas 2008; McMillan et al. 2000). Scientific research may play a more important role in 
stimulating more complex technologies, while for less complex technologies, scientific elements may not be crucial. In this study we focus on the field of nanotechnology, which is of one the promising and key enabling technologies (Heinze 2004; Wang et al. 2013).

Nanotechnology is a branch of technologies that has the ability to work at the atomic and molecular level, and to control matter dimensions between 1 and $100 \mathrm{~nm}$. Nanotechnology is a general purpose technology and can be applied widely in many different fields (Wang et al. 2013). The intensity of application of nanotechnology has been increasing over the years, e.g. more and more anticancer drugs have been developed base on nanotechnology (Coccia and Wang 2015). Partly due to its expected significant impact on economy and society (Bozeman and Youtie 2017; Sargent Jr. 2016), great efforts from public support has been observed in many advanced countries, in particular in the U.S. (Gorsuch and Link 2018).

As an emerging technology, nanotechnology also opens a new window of opportunity for developing countries. A leading position in such a new technology system is believed to be greatly beneficial for the economic catching-up in developing countries and for improving their competitiveness in the long run (Niosi and Reid 2007; Perez and Soete 1988). Among all the developing countries, China has demonstrated enormous efforts in promoting nanotechnology. Extensive financing of nanotechnology research has been set by the National Natural Science Foundation of China, Chinese Academy of Sciences and the State Science and Technology Commission (Bai 2005). In consequence, China's efforts to promote nanotechnology have led to skyrocketing nanotechnology patents and nanotechnology-related publications (Wang et al. 2019).

With the growing attention from both developed and developing countries and the enormous nontechnical research done related to it (as summarized by Gorsuch and Link 2018), little is known about the scientific contribution to the generation of high quality nanotechnology. In particular, being regarded as a science-based technology (Nikulainen and Palmberg 2010), nanotechnology provides an ideal case for studying knowledge flows from science to technology.

Another reason of choosing nanotechnology is that, from a technical perspective, this is a very well defined technological field. The widely accepted international patent classification code (B82) for this field makes the selection of such technologies (based on patents) less arbitrary and more comparable to other research related to this topic.

The patent data used in this study are collected from the DWPI via the platform Derwent Innovation (previously known as Thomson Innovation). Since 2011, all patent offices worldwide have classified nanotechnology uniformly under the International Patent Classification (IPC) system. The old Y01N system has been transformed to the B82Y category. ${ }^{3}$ In the new system, all nanotechnology related patents are classified with an IPC code B82. ${ }^{4}$ In total there are 129,123 patent applications related to nanotechnology in the studied period of 2000-2015. For each patent, both backward citations and forward citations are collected. Backward citations include both patent citations and non-patent citations

\footnotetext{
3 http://www.epo.org/news-issues/issues/classification/nanotechnology.html.

4 There are two sub-categories covered, i.e. B82B and B82Y. The former refers to inventions related to nano-structures formed by manipulations of individual atoms, molecules, or limited collections of atoms or molecules as discrete units; manufacture of treatment thereof. The latter refers to inventions related to specific uses or applications of nano-structures; measurement of analysis of nanostructures; manufacture of treatment of nano-structures (see more at http://www.wipo.int/ipc/itos4ipc/ITSupport_and_download_ area/20130101/pdf/scheme/full_ipc/en/b82.pdf).
} 


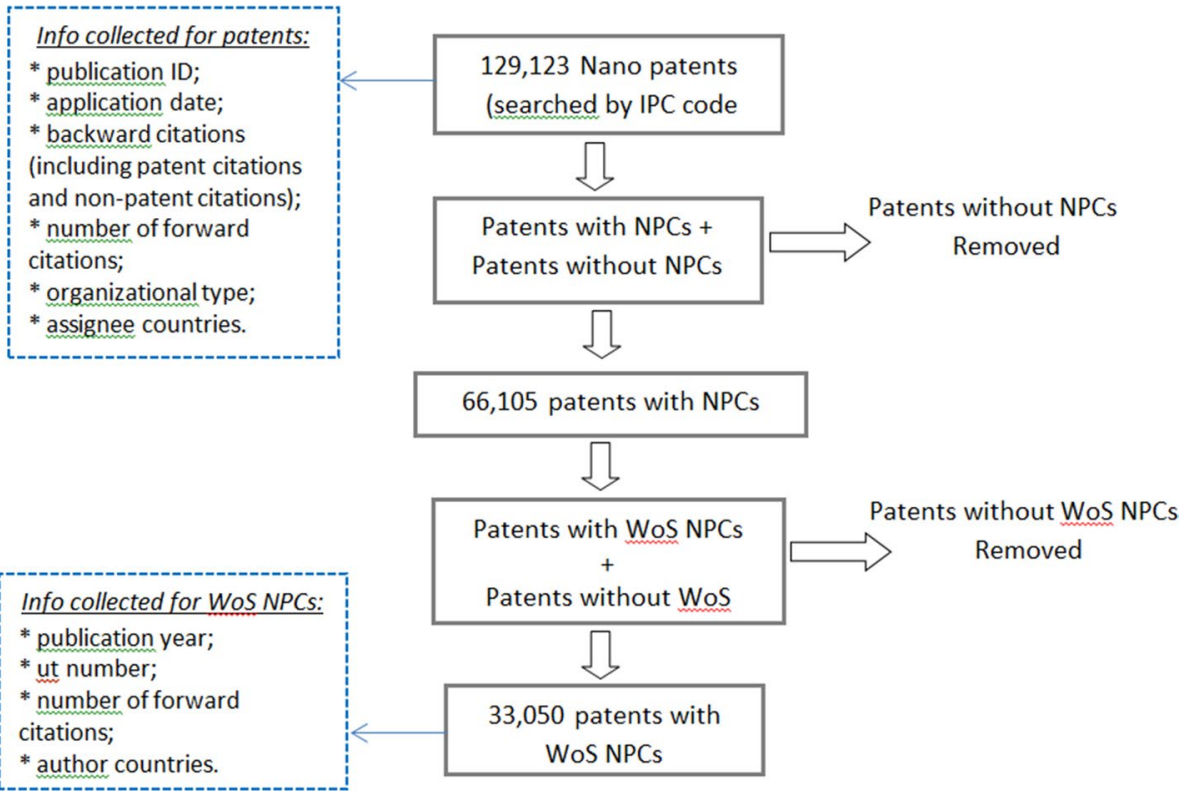

Fig. 1 Steps of data collection

(NPCs). After removing those nano patents without non-patent citations, we obtain 66,105 patents citing non-patent documents (see steps illustrated in Fig. 1). NPCs consist of various types of references, including scientific articles, withdrawn patents, technical manuals, databases, web-based information, news, etc. This study aims to investigate the patents citing scientific articles published in Web of Science (WoS) indexed journals. Based on the DOI and title of the listed non-patent citations in each patent, we identify whether these NPCs are indexed by WoS journals. If they are not, we remove the patents from our sample. This step results in 33,050 nano patents. ${ }^{5}$

Based on the information of assignees, the above patents are classified into three organizational types: (1) patents developed by firms, (2) patents developed by research institutes and universities, ${ }^{6}$ and (3) firm-university collaborated patents. Country codes are extracted based on the addresses of inventors. For each patent, we collect its publication ID, application date, backward citations (including number of cited patents and number of cited WoS publications), number of forward citations, and assignee countries. For the cited WoS publications, we collect the information on publication year, ut number, ${ }^{7}$ number of forward citations, countries of authors.

This study aims to explore the impact of scientific research on the quality of technologies. Patent forward citations are collected to represent the impact or quality of the investigated technology.

\footnotetext{
${ }^{5}$ Scientific references (added by examiners) with a publication year later than the patent publication year are removed.

${ }^{6}$ This type of patent is also called university patents in this paper.

7 This is the accession number, a unique identifying number associated with each record indexed in Web of Science.
} 
For each nano patent, we construct the following indicators.

Scope of technological background is represented by the number of cited patents (nr cited_patents), $\sum P_{i}$. If a great number of patents have been cited by one new invention, this indicates that this new invention was developed based on a wide range of technologies. Otherwise, the scope of technological background is regarded as narrow.

Scope of scientific background is denoted by the number of cited WoS articles (nr_ cited_pubs), $\sum S_{i}$. Similar to the previous indicator, citing more scientific publications indicates a wider scope of scientific background.

Newness of cited scientific articles is measured by the average publication year of the cited WoS articles. Suppose one nano patent cited N WoS scientific articles and the publication year of each article is expressed as $Y S_{i}$, then the value of newness of cited scientific articles can be calculated by $\frac{\sum_{i=1}^{N} Y S_{i}}{N}$. A lower newness value indicates that this group of cited scientific articles is on average relatively old, while a higher newness value indicates that this patent has been developed based on a group of more recent scientific articles.

To measure scientific or technological quality, citation is a commonly used proxy (Popp 2017). Quality of cited scientific articles is represented by the average forward citations of these cited scientific articles. If one nano patent cited $\mathrm{N}$ WoS scientific articles and the forward citation of each article is $F C S_{i}$, then the average forward citation of this group of scientific articles can be measured by $\frac{\sum_{i=1}^{N} F C S_{i}}{N}$. A higher level of average forward citation implies that a group of high-quality scientific research has been used in developing this studied nano patent. A lower level of average citation implies that this nano patent has been developed based on less impactful (or relatively unknown) scientific articles.

Variety of scientific knowledge resources is measured by the number of author countries of the cited scientific articles. Duplicates have been removed from the list of countries. For instance, if a nano patent cites three WoS articles and the author countries for these three articles are U.S., Netherlands, and U.S., respectively, the value of 'variety of scientific knowledge resources' for this patent is counted as two. ${ }^{8}$

To further explore different types of knowledge resources, we rely on the list of country names of authors. We use cited WoS articles from the U.S. to represent knowledge flows from advance countries, and cited WoS articles from China to represent knowledge flows from emerging economies. Given that the nature of patents developed by industry is different from that of patents developed by universities (Henderson et al. 1998), we separate firm patents from university patents in most models.

Poisson and Negative Binomial are two types of regression used often to model count data. In our case, to evaluate the effect of various factors on the forward citations of nano patents, we experimented with both regression types and results stayed rather similar. Nevertheless, due to the over-dispersion feature of the outcome variable (i.e. the variance with each sub-group is higher than the mean within each sub-group), we choose to use the set of Negative Binomial regressions. Results from Poisson regressions are reported in the "Appendix" for robustness check. The Negative Binomial regression model used in this study can be expressed as follows (see also in Greene 2008):

$$
\begin{aligned}
& f\left(y_{i} \mid x_{i}, \delta_{i}\right)=\frac{e^{-\mu_{i} \delta_{i}}\left(\mu_{i} \delta_{i}\right)^{y_{i}}}{y_{i} !}, j=0,1,2 \ldots \\
& \mu_{i}=\exp \left(\beta_{0}+\beta_{1} x_{1}+\beta_{2} x_{2}+\beta_{3} x_{3}+\beta_{4} x_{4}+\beta_{5} x_{5}+\delta_{i}\right)
\end{aligned}
$$

8 The country name of U.S. is counted once. 
where $y_{i}$ is the number of forward citations of patent $i$ and $\mu_{i}$ is the conditional mean. $\delta_{i}$ is an error term that relaxes the Poisson assumption that the mean equals the variance (See Greene 2008, p. 910). $x_{1}-x_{5}$ are the five independent variables representing scope of technological background, scope of scientific background, newness of cited scientific articles, quality of cited scientific articles, and variety of scientific knowledge resources.

\section{Results and discussion}

Considering the fact that the invention pattern of firms is different from that of research institutes or universities (Wang and Li 2018), we provide a separate analysis of patents from different organizational types. Table 1 reports a summary of the main statistics for the variables used in our analysis. The scope of technological background (i.e. number of cited patents) varies greatly, ranging from 0 to 2197 for nano patents developed by firms and 0 to 824 for those developed by research institutes and universities. On average, the number of patents cited by firm patents is remarkably higher than that of university patents, with a mean of 30.44 for the former group and 8.75 for the latter. This shows that, as expected, innovation performance carried by firms is more closely related to the market than innovation performance carried by university.

The distribution of cited literature is highly skewed (Popp 2017). Hence we take natural logarithms for the independent variables (except average year of cited WoS publications which is a variable with normal distribution).

Given that there is a time lag in receiving citations, it is of importance to take the age of patents into consideration. The likelihood ratio test has been performed by comparing the models without year dummies and those with year dummies. The test shows that the latter group fits significantly better than the former group (prob $>$ chi $2=0.0000$ ). Therefore, regressions in this study all include year dummies. ${ }^{9}$ To a lesser degree, the national economic environment may also influence the patenting performance in one country. Hence, we use the cluster function in the regression models ${ }^{10}$ to capture the differences between countries. $^{11}$

Table 2 documents the regression results of three samples: (1) all patents, (2) firm patents and (3) university patents. ${ }^{12}$ Given that Scientific scope (nr_cited_pub) and Variety of scientific resources (nr_all_country) are highly correlated, these two variables are included in separate models.

Technological scope (i.e. number of cited patents) has a significant and positive effect on the dependent variable (i.e. forward citations of nano patents) in all models, including the full sample (Models 1 and 2), sub-sample of firm patents (Models 3 and 4) and sub-sample of university patents (Models 5 and 6). The second variable, scientific scope (i.e. number of cited WoS publications) is positively significant in all three models. This implies that a wider scope of scientific references is likely to lead to a higher patent quality. With regard to the third variable, newness of scientific knowledge, there is a slight difference between firm patents and university patents. The coefficient values are higher and

\footnotetext{
9 Based on the publication years of patent applications.

10 The Akaike information criterion (AIC) and Bayesian information criterion (BIC) both suggest that models with country clusters perform better than those without.

11 Based on the assignee countries.

12 Firm-university collaborated patents are not included in the sub-samples.
} 


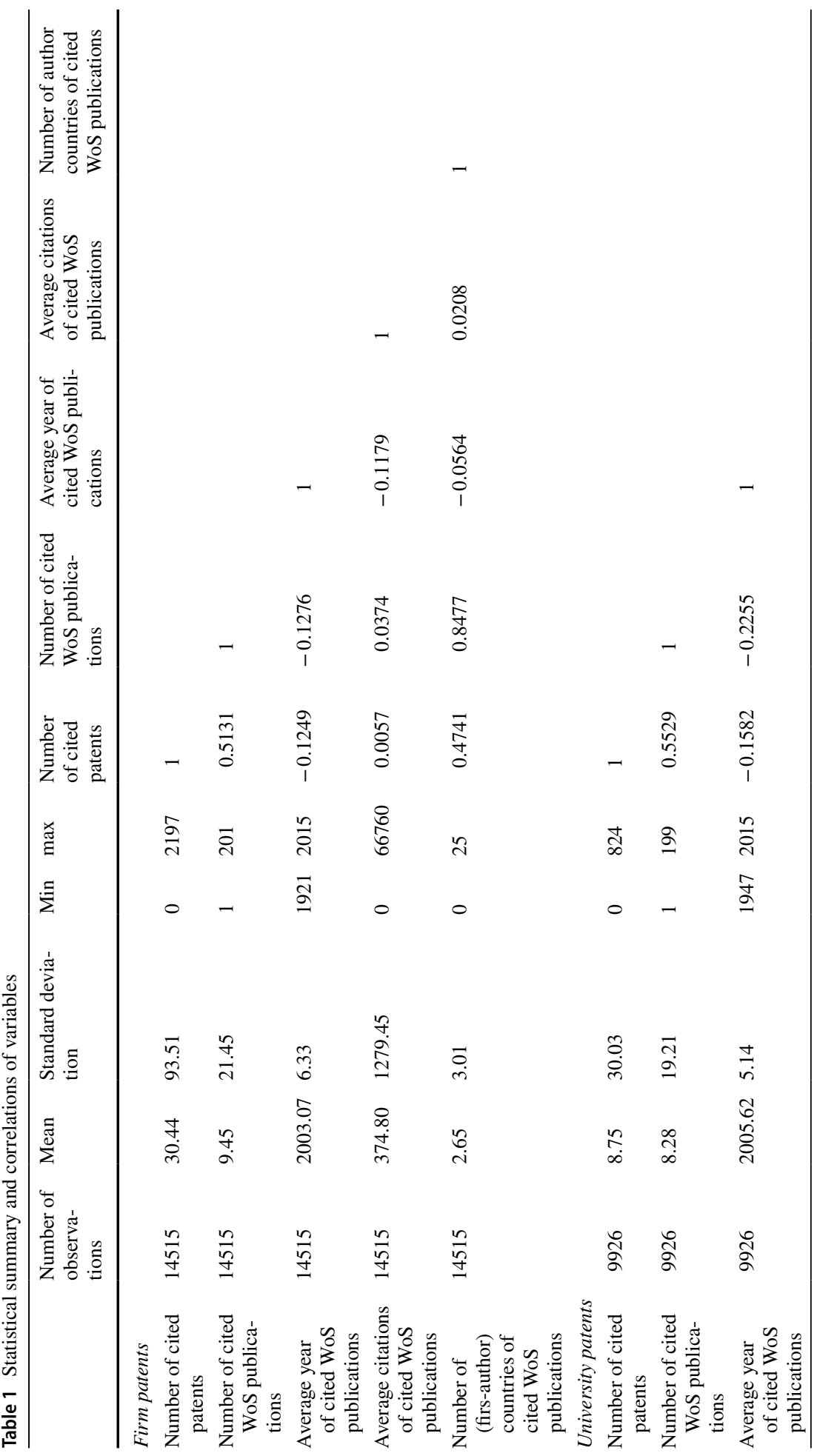




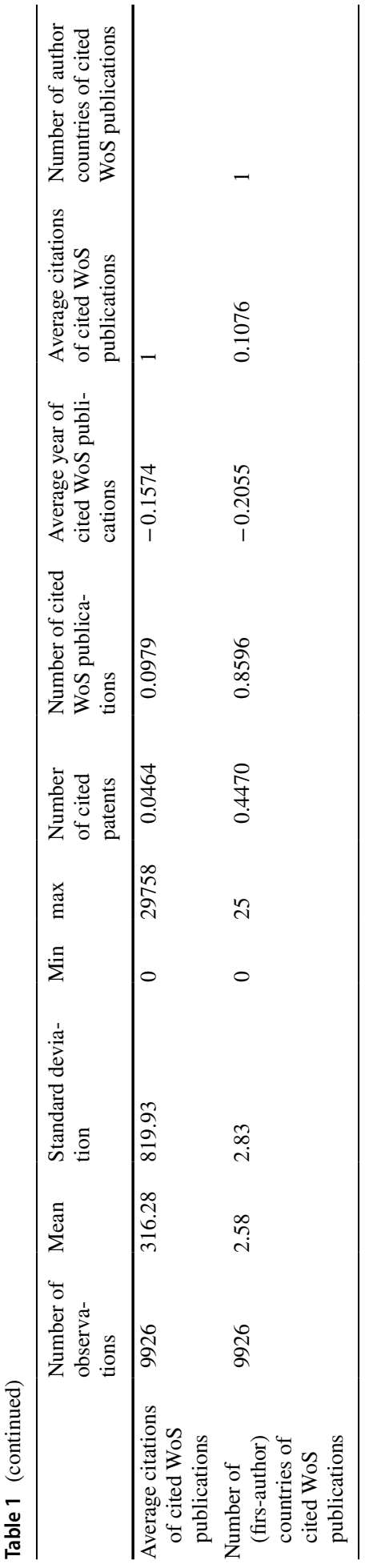

글 Springer 


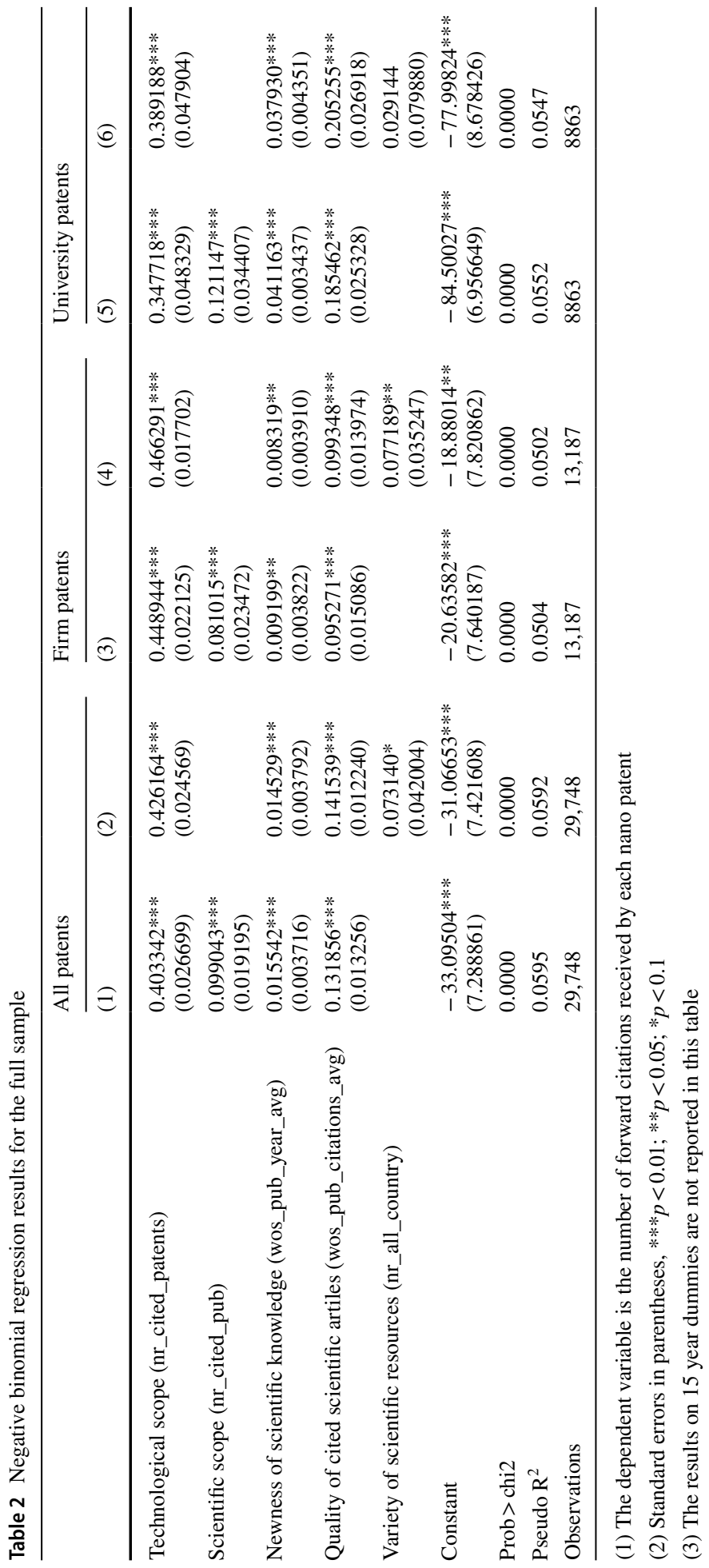




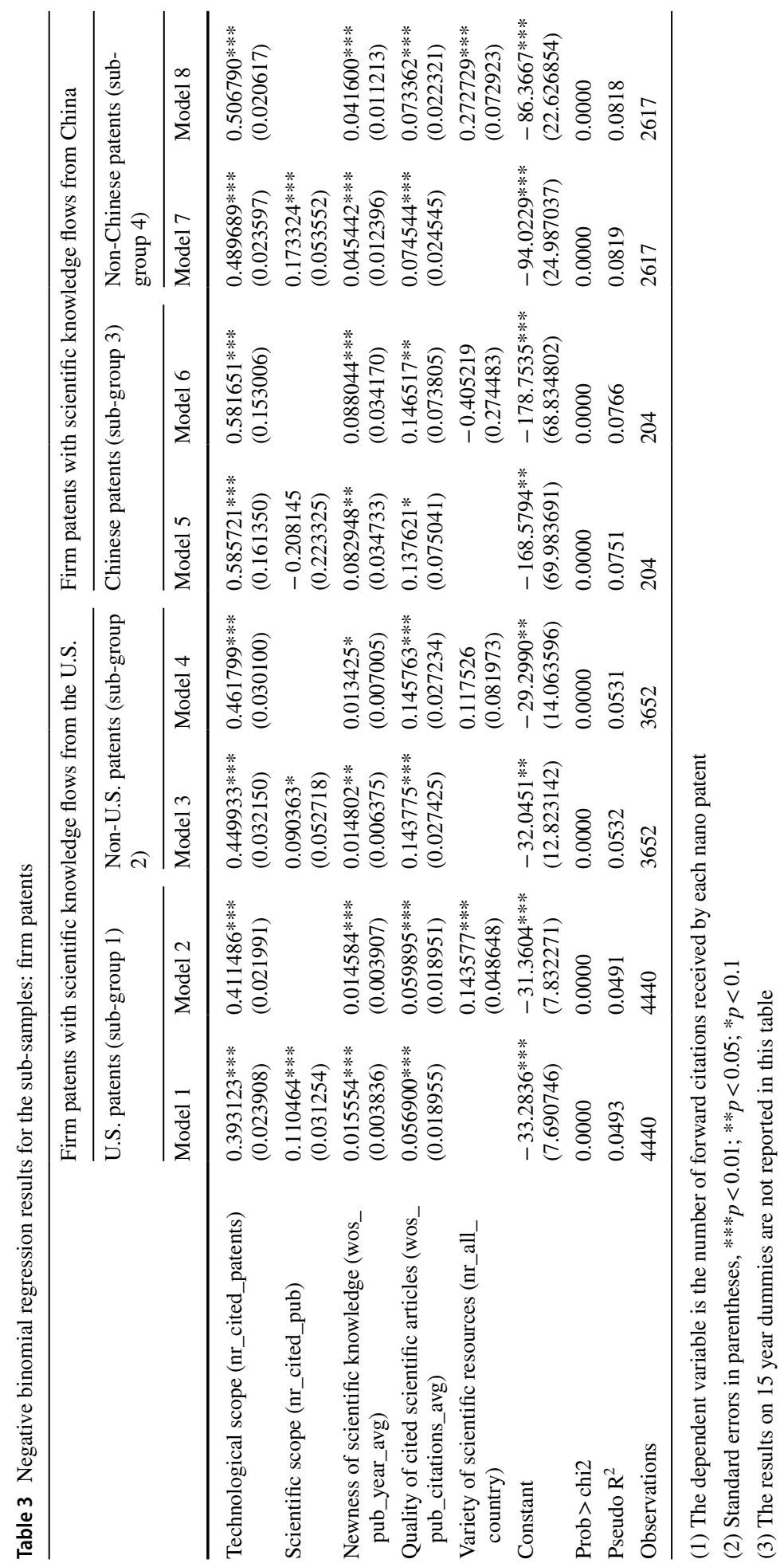




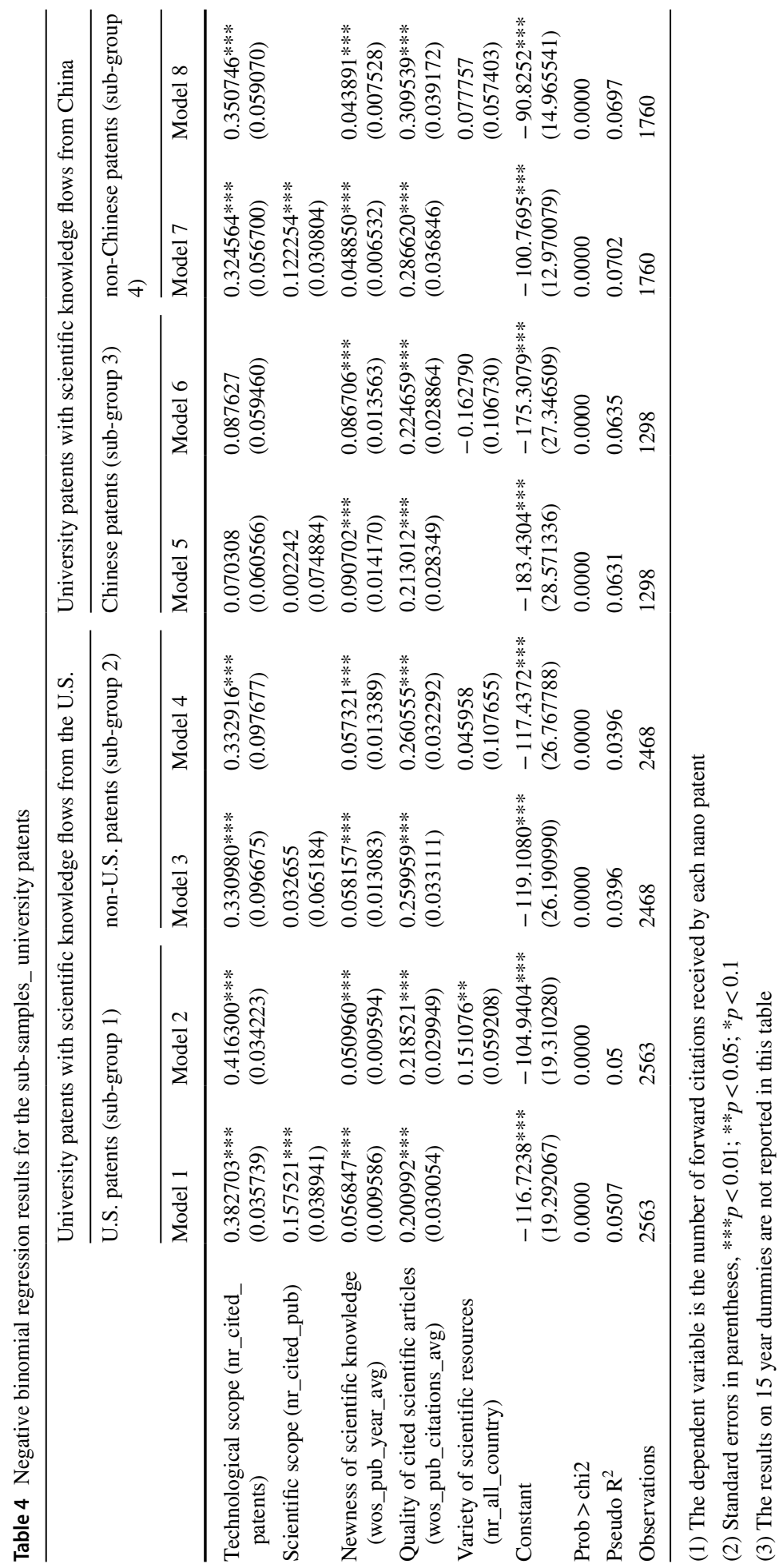


more significant for university patents (Models 5 and 6) than those firm patents (Models 3 and 4), indicating that citing more recent scientific publications is more beneficial to university inventions. This issue will be further explained later in Tables 3 and 4.

Regarding the issue whether the quality of science plays a role, results in Table 2 show that the quality of cited scientific articles (forward citations of cited WoS publications) has a positive effect on the quality of citing patents. This positive effect is highly significant for all models at the 0.01 level, indicating that a patent developed based on a group of highquality scientific research is likely to receive more forward citations itself in the future.

Variety of scientific knowledge resources has a significant coefficient in the full sample models. However, such effect is found to be higher and more significant in the firm patent group than the university patent group. This points out that it is more valuable for firm patents (rather than university patents) to refer to scientific knowledge from various origins. Year dummies are highly significant for all models, which can be explained by the time lag of forward citations.

Following the results in Table 2, we extend the analysis to explore the effect of knowledge resources on patent quality. We use WoS references from the U.S. to represent knowledge flows from advanced countries, and WoS references from China to represent knowledge flows from emerging economies. The knowledge recipients are divided into home and foreign groups. The former stands for the group of patents developed in the same country as the knowledge resource origin, and the later represents the group of patents developed by foreign countries. Considering the aforementioned different nature of inventions developed by different organizational types, firm patents and university patents are tested separately in Tables 3 and 4 .

For patents developed by firms, Table 3 includes four sub-groups, i.e. knowledge flows from the U.S. (sub-groups 1 and 2) and knowledge flows from China (sub-groups 3 and 4). Results show that, similar to the aggregated results in Table 2, technological scope (i.e. number of cited patents) has a positive and significant effect on the quality of citing patents, irrespective of countries of knowledge resources.

The results on scientific scope (i.e. number of cited publications) are mixed, as they depend on the organizational types and knowledge resource countries. A wide scientific scope has a significant positive effect on patents citing scientific articles from the U.S. (Models 1 and 3). However, for the sample with scientific knowledge flows from China, this variable presents a non-significant effect in the home patent group (i.e. Chinese patents, in Model 3) while a positive and significant effect is presented in the foreign patent group (i.e. patents developed by foreign countries, in Model 4).

In terms of newness of scientific knowledge, there is also a noticeable difference between different patent groups. In the sample with knowledge flows from the U.S. (Models 1-4), a more significant and slightly higher coefficient is observed for home patents (Models 1 and 2) compared to foreign patents (Models 3 and 4). In the sub-sample for patents receiving knowledge flows from China (Models 5-8), the effect for home patents is almost twice as high as those for non-Chinese patents. That is, more recent scientific research is more beneficial to home patents developed by Chinese inventors (Models 5 and 6) than patents developed by non-Chinese inventors (Models 7 and 8). In general, this shows that more recent scientific knowledge is beneficial to patents developed by inventors from the same countries as the knowledge origins. For crossing knowledge flows-i.e. the knowledge resource country is different from the patent inventor country-relatively earlier knowledge is more beneficial. Among all the different groups, Chinese patents citing scientific knowledge from China have the highest coefficients, 0.08295 in Model 5 and 0.08804 in Model 6. As shown in Table 5, the average year of cited WoS articles in this sub-group (home patents citing 
Chinese science) is 2008.5. This is remarkably higher than that of the U.S. case (home patents citing American science) which is 2002.5. This might be due to the fact that science developed mainly in recent years in the emerging countries such as China.

Similar to the results in Table 2, the quality of cited scientific articles is statistically significant and positive in all models in Table 3. This supports our hypothesis that highquality scientific knowledge can help improve the quality of patents.

The variety of scientific knowledge resources has a significant and positive coefficient in sub-groups 1 and 4 . This is consistent with the variable of scientific scope. In Model 4 (sub-group 2), this variable is positive but non-significant, in line with the variable of scientific scope. This shows that, in most cases, it is more beneficial to have a higher level of variety of scientific resources or scientific scope. However, for Chinese patents developed based on Chinese science (sub-group 3, Model 6), the variety of scientific resources has a negative contribution to the quality of citing patents. This indicates that more scientific publications and a higher diversity of author countries do not lead to a higher quality in the Chinese patents developed based on Chinese science.

Table 4 reports the regression results for university patents, with distinguished scientific knowledge flows from the U.S. and China. Most of the regression results in Table 4 are in line with those in the firm-patent sample in Table 3. A major difference is that, compared to Table 3, the coefficients of technological scope are not significant in sub-group 3 in Table 4. This indicates that the scope of technological background does not have a significant effect on the quality of Chinese patents developed base on Chinese scientific knowledge. In fact, the average level of scientific scope in sub-group 3 is much lower than in the U.S. (sub-group 1), i.e. 3.1 versus 19.8 for firm patents and 3.2 versus 20.5 for university patents (see in Table 5 in the "Appendix"). Similarly, on average variety of scientific resources in sub-group 3 is also remarkable lower than the mean of this variable in the U.S., i.e. 1.8 versus 4.3 for firm patents and 1.5 versus 4.5 for university patents. This indicates that, for the group of Chinese patents developed based on Chinese science, scientific scope and the variety of scientific knowledge resources is considerably low.

Given the heterogeneous nature of scientific knowledge and the associated contribution to technological advancement in different sub-groups, regressions in Tables 3 and 4 are preferable to those in Table 2.

Robustness check was conducted using another count data model-Poisson model (see Tables 6, 7, 8 in the "Appendix"). Results stay similar to those from Negative Binomial regressions, confirming the significant contribution from scientific scope, newness of scientific knowledge, quality of cited scientific article to patent quality. It also points out the difference between country origins of knowledge in the process of producing impactful patents, in particular related to the scientific scope and variety of scientific resources.

Following the observed different patterns across different sub-groups, a one-way ANOVA was conducted to compare the effect of scientific knowledge (i.e. scientific scope, newness of scientific knowledge, quality of cited scientific article, and variety of scientific resources) for different country groups. Regarding scientific scope, there was a statistically significant difference between countries as determined by one-way ANOVA ( $\mathrm{F}(54$, $13,132)=33, p=0.0000$ ) for firm patents and $\mathrm{F}(51,8811)=39, p=0.0000$ for university patents). The significant difference also holds for newness of scientific knowledge, ${ }^{13}$ quality

13 The statistically significant difference between countries is determined by one-way ANOVA (F $(54$, $13,162)=12, p=0.0000$ ) for firm patents and $\mathrm{F}(51,8811)=35, p=0.0000$ for university patents). 
of cited scientific article, ${ }^{14}$ and variety of scientific resources. ${ }^{15}$ The results, in line with Narin et al. (1997) and McMillan et al. (2000), confirm that there is a strong national bias in the citation patterns in the field of nanotechnology.

\section{Conclusions}

In order to understand what types of scientific knowledge can help generate impactful technologies, this paper uses nano patents data collected from the DWPI and extracts both patent citations and non-patent citations (NPCs) for each patent. By linking the quality of patents with the characteristics of NPCs (including their information from Web of Science), this study investigates how science can help improve the quality of new technologies.

On the one hand, our study shows that science can help improve the quality of patents in many different ways. This, in accordance with Sorenson and Fleming (2004), emphasizes the importance of S\&T linkages.

On the other hand, this study stresses that the science-technology linkage patterns can differ across countries. There are also differences between organizations, as well as knowledge origins. This corresponds to the heterogeneous nature of knowledge sources stressed by Audretsch and Link (2019). In our empirical study, we find that more recent scientific knowledge has a more significant contribution to the quality of patents. In most cases, this effect is stronger for university patents than for firm patents. Compared to the U.S., China's patents seem to benefit greatly from recently published scientific research. This might be explained by the fact that, as an emerging country, China's patents focus more on emerging technologies, rather than mature technologies. Hence, more recent science is more relevant in China.

Our results suggest that a wider scientific scope and a high level of variety of scientific resources do not always lead to a higher patent quality. A specific case is that, when Chinese patents are developed based on Chinese science-in which case the scientific scope and variety level is very low-the significant positive contribution is missing. To some extent, in line with Appio et al. (2017), this proves our hypothesis that public science with a larger scope does not always lead to higher-quality inventions.

Irrespective of patent types or country origins, our findings show that the quality of cited science has always been crucial in affecting the quality of citing patents. A highquality scientific base can help lead to a high-quality patent.

As public knowledge in science is freely available to organizations and inventors all around the world, this sheds light on science-technology interactions not only within one country, but also between different countries. The science from advanced countries can be an important knowledge resource for developing countries. While promoting science-technology linkages in one country, it is of importance to take the international dimension of knowledge flows into consideration. Knowledge transfers from science conducted by leading countries play an important role in supporting technology development in latecomer countries. In the catching up progress, it is beneficial for latecomer countries to learn from and utilize the scientific knowledge from advanced countries. Our findings also strengthen the importance of international knowledge spillovers.

\footnotetext{
14 The statistically significant difference between countries is determined by one-way ANOVA ( $\mathrm{F}(54$, $13,132)=6, p=0.0000)$ for firm patents and $\mathrm{F}(51,8811)=26, p=0.0000$ for university patents).

15 The statistically significant difference between countries is determined by one-way ANOVA (F $(54$, $13,132)=21, p=0.0000)$ for firm patents and $\mathrm{F}(51,8811)=26, p=0.0000$ for university patents).
} 
This calls for future attention to stimulating science-technology interactions. It is beneficial, in particular for inventors in firms, to be aware of scientific research, no matter the country origins. By bringing related scientific research to the sight of industry, one may help spur more valuable innovations.

The analyses of this study are based on patent citations. Although citation analysis provides important means to track knowledge flows, it is limited to published scientific research. Citations reveal the formal and direct linkages between science and technology. Nevertheless, the informal or indirect linkages beyond citation analysis can be subjects of future studies.

Acknowledgements The author Lili Wang would like to thank the support from Beijing Academy of Science and Technology (BJAST) and Beijing Research Centre for Science of Science (BJSS).

Open Access This article is distributed under the terms of the Creative Commons Attribution 4.0 International License (http://creativecommons.org/licenses/by/4.0/), which permits unrestricted use, distribution, and reproduction in any medium, provided you give appropriate credit to the original author(s) and the source, provide a link to the Creative Commons license, and indicate if changes were made.

\section{Appendix}

See Tables 5, 6, 7 and 8 .

Table 5 Summary statistics for sub-groups

\begin{tabular}{|c|c|c|c|c|c|c|c|c|}
\hline & \multicolumn{2}{|c|}{$\begin{array}{l}\text { Sub-group } 1 \\
\text { ( } 4440 \text { obser- } \\
\text { vations) }\end{array}$} & \multicolumn{2}{|c|}{$\begin{array}{l}\text { Sub-group } 2 \\
\text { (3652 obser- } \\
\text { vations) }\end{array}$} & \multicolumn{2}{|c|}{$\begin{array}{l}\text { Sub-group } 3 \\
\text { ( } 204 \text { observa- } \\
\text { tions) }\end{array}$} & \multicolumn{2}{|c|}{$\begin{array}{l}\text { Sub-group } \\
4 \text { ( } 2617 \text { obser- } \\
\text { vations) }\end{array}$} \\
\hline & Mean & SD & Mean & SD & Mean & SD & Mean & SD \\
\hline \multicolumn{9}{|l|}{ Firm patents } \\
\hline Number of cited patents & 61.7 & 119.6 & 27.1 & 117.4 & 5.9 & 15.8 & 51.9 & 120.4 \\
\hline Number of cited WoS publications & 19.8 & 31.0 & 8.8 & 20.6 & 3.1 & 3.3 & 18.9 & 30.3 \\
\hline Average year of cited WoS publications & 2002.5 & 6.1 & 2003.3 & 5.5 & 2008.5 & 3.9 & 2004.6 & 4.2 \\
\hline $\begin{array}{l}\text { Average citations of cited WoS publica- } \\
\text { tions }\end{array}$ & 444.6 & 951.2 & 444.8 & 918.3 & 197.9 & 400.5 & 352.1 & 702.3 \\
\hline \multirow{3}{*}{$\begin{array}{l}\text { Number of (firs-author) countries of cited } \\
\text { WoS publications }\end{array}$} & 4.3 & 4.2 & 2.8 & 2.6 & 1.8 & 1.4 & 4.9 & 4.2 \\
\hline & \multicolumn{2}{|c|}{$\begin{array}{l}\text { Sub-group } 1 \\
\text { ( } 2563 \text { obser- } \\
\text { vations) }\end{array}$} & \multicolumn{2}{|c|}{$\begin{array}{l}\text { Sub-group } 2 \\
\text { ( } 2468 \text { obser- } \\
\text { vations) }\end{array}$} & \multicolumn{2}{|c|}{$\begin{array}{l}\text { Sub-group } 3 \\
\text { (1298 obser- } \\
\text { vations) }\end{array}$} & \multicolumn{2}{|c|}{$\begin{array}{l}\text { Sub-group } \\
4 \text { ( } 1760 \text { obser- } \\
\text { vations) }\end{array}$} \\
\hline & Mean & SD & Mean & SD & Mean & SD & Mean & SD \\
\hline \multicolumn{9}{|l|}{ University patents } \\
\hline Number of cited patents & 20.7 & 55.8 & 6.3 & 11.2 & 3.3 & 4.5 & 12.8 & 27.0 \\
\hline Number of cited WoS publications & 20.5 & 33.4 & 6.8 & 9.8 & 3.2 & 6.8 & 16.8 & 26.2 \\
\hline Average year of cited WoS publications & 2003.8 & 4.6 & 2005.9 & 4.4 & 2010.3 & 3.3 & 2005.3 & 4.3 \\
\hline $\begin{array}{l}\text { Average citations of cited WoS publica- } \\
\text { tions }\end{array}$ & 486.6 & 897.9 & 375.4 & 728.9 & 123.7 & 323.8 & 371.4 & 555.6 \\
\hline $\begin{array}{l}\text { Number of (firs-author) countries of cited } \\
\text { WoS publications }\end{array}$ & 4.3 & 4.4 & 2.9 & 2.2 & 1.5 & 1.3 & 4.8 & 3.8 \\
\hline
\end{tabular}




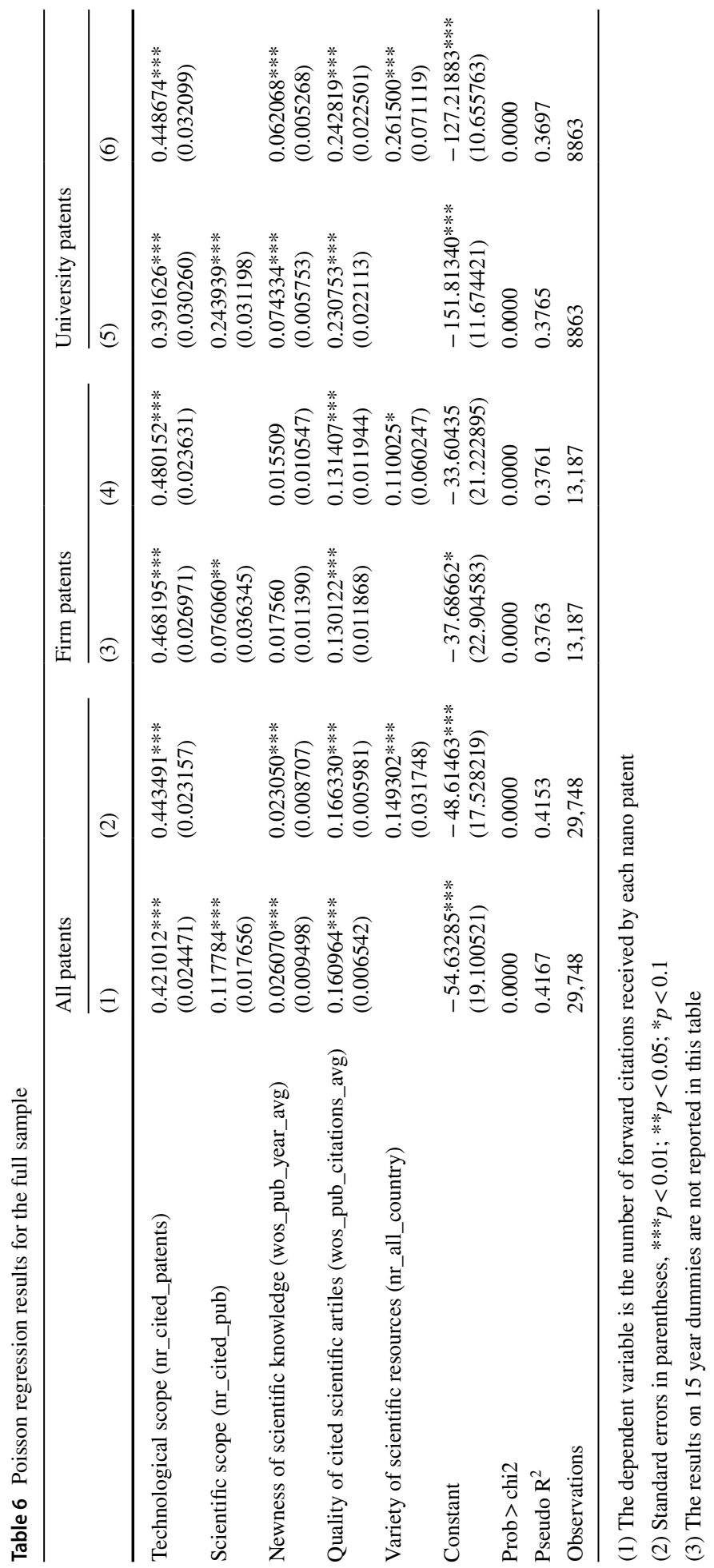




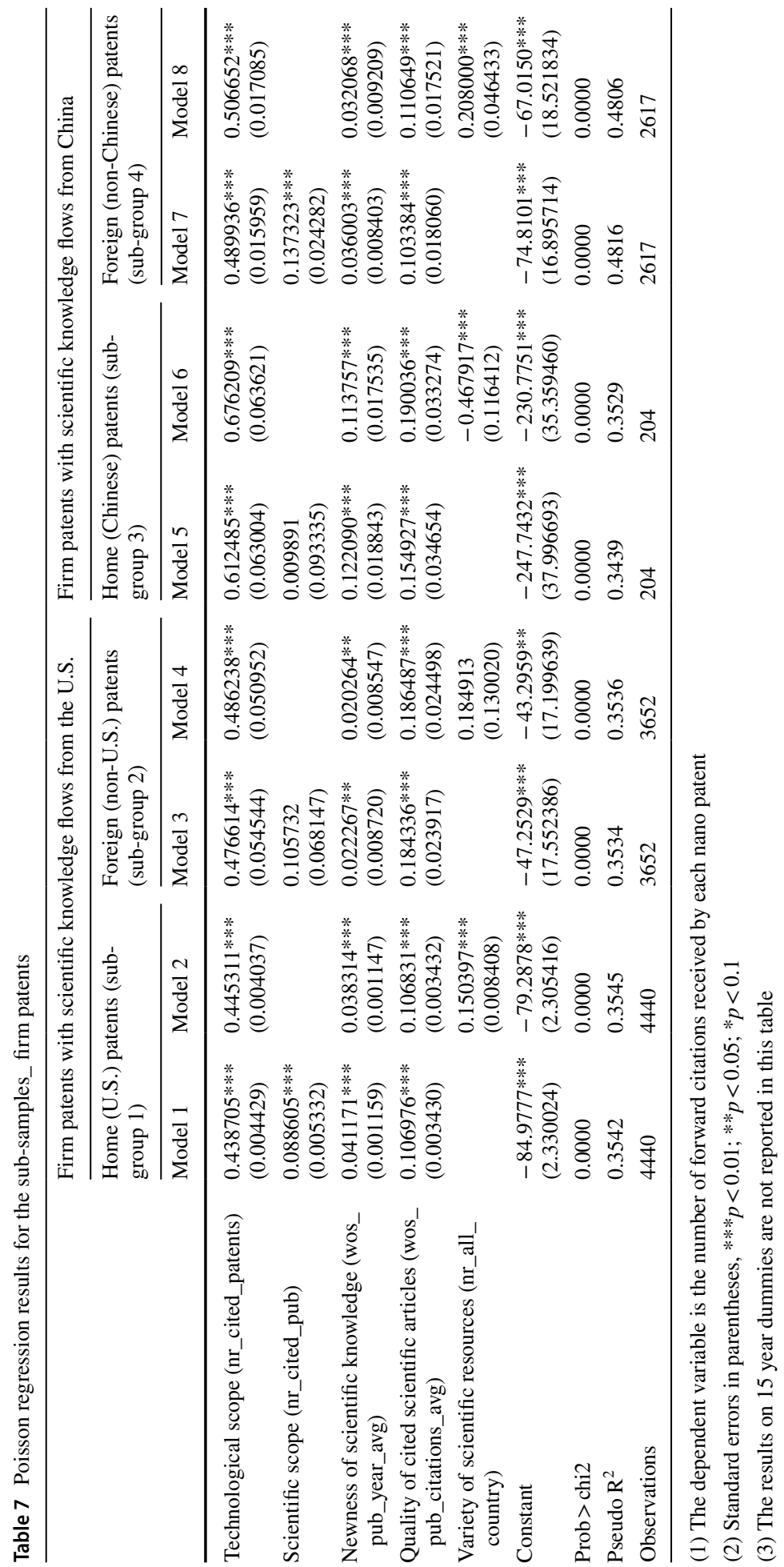




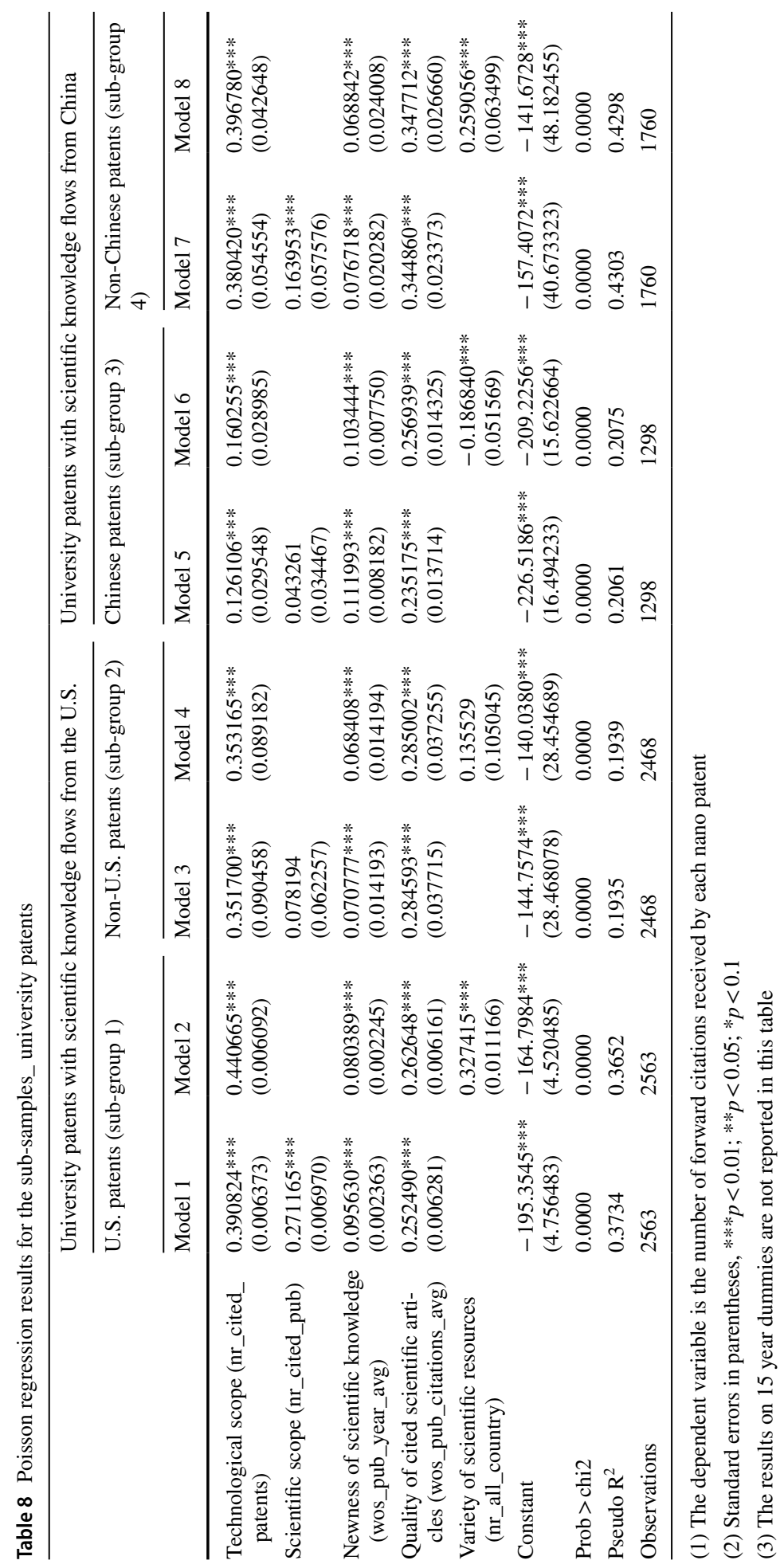




\section{References}

Acs, Z., Anselin, L., \& Varga, A. (2002). Patents and innovation counts as measures of regional production of new knowledge. Research Policy, 31(7), 1069-1085. https://doi.org/10.1016/S0048 -7333(01)00184-6.

Acs, Z. J., Audretsch, D. B., \& Feldman, M. P. (1994). R\&D spillovers and recipient firm size. The Review of Economics and Statistics, 76(2), 336-340.

Adams, J. D. (1990). Fundamental stocks of knowledge and productivity growth. Journal of Political Economy, 98(4), 673-702.

Antonelli, C. (2007). Technological knowledge as an essential facility. Journal of Evolutionary Economics, 17(4), 451-471. https://doi.org/10.1007/s00191-007-0058-4.

Appio, F. P., Martini, A., \& Fantoni, G. (2017). The light and shade of knowledge recombination: Insights from a general- purpose technology. Technological Forecasting and Social Change, 125(May), 154-165. https://doi.org/10.1016/j.techfore.2017.07.018.

Audretsch, D. B., \& Feldman, M. (1996). R\&D spillovers and the geography of innovation and production. The American Economic Review, 86(3), 630-640.

Audretsch, D. B., \& Feldman, M. P. (2004). Knowledge spillovers and the geography of innovation. In J. V. Henderson \& J.-F. Thisse (Eds.), Handbook of regional and urban economics (Vol. 4, pp. 2713-2739). Amsterdam: North Holland.

Audretsch, D. B., \& Link, A. N. (2019). Sources of knowledge and entrepreneurial behavior. TorontoBuffalo-London: University of Toronto Press.

Autant-Bernard, C., Fadairo, M., \& Massard, N. (2013). Knowledge diffusion and innovation policies within the European regions: Challenges based on recent empirical evidence. Research Policy, 42(1), 196-210. https://doi.org/10.1016/j.respol.2012.07.009.

Bai, C. (2005). Ascent of nanoscience in China. Science, 309(5731), 61-63.

Beise, M., \& Stahl, H. (1999). Public research and industrial innovations in Germany. Research Policy, 28, 397-422.

Bekkers, R., \& Bodas Freitas, I. M. (2008). Analysing knowledge transfer channels between universities and industry: To what degree do sectors also matter? Research Policy, 37, 1837-1853. https://doi. org/10.1016/j.respol.2008.07.007.

Bozeman, B., \& Youtie, J. (2017). Socio-economic impacts and public value of government-funded research: Lessons from Four US National Science Foundation initiatives. Research Policy, 46(8), 1387-1398.

Branstetter, L. (2005). Exploring the link between academic science and industrial innovation. Annales d'Économie et de Statistique. https://doi.org/10.2307/20777572.

Branstetter, L. G. (2001). Are knowledge spillovers international or intranational in scope? Microeconometric evidence from the U.S. and Japan. Journal of International Economics, 53(1), 53-79. https ://doi.org/10.1016/s0022-1996(00)00068-4.

Calcagnini, G., Favaretto, I., Giombini, G., Perugini, F., \& Rombaldoni, R. (2016). The role of universities in the location of innovative start-ups. Journal of Technology Transfer, 41(4), 670-693. https:// doi.org/10.1007/s10961-015-9396-9.

Coccia, M., \& Wang, L. (2015). Path-breaking directions of nanotechnology-based chemotherapy and molecular cancer therapy. Technological Forecasting and Social Change, 94, 155-169.

Cohendet, P., \& Meyer-Krahmer, F. (2001). The theoretical and policy implications of knowledge codification. Research Policy, 30(9), 1563-1591. https://doi.org/10.1016/S0048-7333(01)00168-8.

Feldman, M. P. (1999). The new economics of innovation, spillovers and agglomeration: A review of empirical studies. Economics of Innovation and New Technology, 8(1-2), 5-25. https://doi. org/10.1080/10438599900000002.

Feldman, M. P., \& Audretsch, D. B. (1999). Innovation in cities: Science-based diversity, specialization and localized competition. European Economic Review, 43, 409-429. https://doi.org/10.1080/00343 400801922814.

Fernández-Ribas, A. A., \& Shapira, P. (2009). Technological diversity, scientific excellence and the location of inventive activities abroad: The case of nanotechnology. Journal of Technology Transfer, 34(3), 286-303. https://doi.org/10.1007/s10961-008-9090-2.

Finardi, U. (2011). Production of scientific knowledge and its technological exploitation. Scientometrics, 89(1), 37-50. https://doi.org/10.1007/s11192-011-0443-5.

Fritsch, M. (2002). Measuring the quality of regional innovation systems: A knowledge production function approach. International Regional Science Review, 25(1), 86-101.

Fritsch, M., \& Franke, G. (2004). Innovation, regional knowledge spillovers and R\&D cooperation. Research Policy, 33(2), 245-255. https://doi.org/10.1016/S0048-7333(03)00123-9. 
Gorsuch, J., \& Link, A. N. (2018). Nanotechnology: A call for policy research. Annals of Science and Technology Policy, 2(4), 307-463. https://doi.org/10.1561/110.00000008.

Greene, W. (2008). Functional forms for the negative binomial model for count data. Economics Letters, 99(3), 585-590. https://doi.org/10.1016/j.econlet.2007.10.015.

Griliches, Z. (1979). Issues in assessing the contribution of research and development to productivity. The Bell Journal of Economics, 10(1), 92-116.

Grossman, G. M., \& Helpman, E. (1990). Trade, innovation, and growth. American Economic Review, $80(2), 86-91$.

Heinze, T. (2004). Nanoscience and Nanotechnology in Europe: Analysis of publications and patent applications including comparisons with the United States. Nanotechnology Law \& Business, 1(4), 1-19.

Henderson, R., Jaffe, A. B., \& Trajtenberg, M. (1998). Universities as a source of commercial technology: A detailed analysis of university patenting, 1965-1988. Review of Economics and Statistics, 80(1), 119-127. https://doi.org/10.1162/003465398557221.

Hoekman, J., Frenken, K., \& van Oort, F. (2009). The geography of collaborative knowledge production in Europe. Annals of Regional Science, 43, 721-738. https://doi.org/10.1007/s00168-008-0252-9.

Jaffe, A. B., \& Trajtenberg, M. (1996). Flows of knowledge from universities and federal laboratories: Modeling the flow of patent citations over time and across institutional and geographic boundaries. Proceedings of the National Academy of Sciences of the United States of America, 93(23), 12671-12677. https://doi.org/10.1073/pnas.93.23.12671.

Jaffe, A. B., \& Trajtenberg, M. (2002). Patents, citations \& innovations: A window on the knowledge economy. Cambridge, MA: Massachusetts Institute of Technology. https://doi.org/10.1017/CBO9781107 415324.004.

Keijl, S., Gilsing, V. A., Knoben, J., \& Duysters, G. (2016). The two faces of inventions: The relationship between recombination and impact in pharmaceutical biotechnology. Research Policy, 45(5), 10611074. https://doi.org/10.1016/j.respol.2016.02.008.

Liao, Y. C., \& Phan, P. H. (2016). Internal capabilities, external structural holes network positions, and knowledge creation. Journal of Technology Transfer, 41(5), 1148-1167. https://doi.org/10.1007/s1096 1-015-9415-X.

Malo, S., \& Geuna, A. (2000). Science-technology linkages in an emerging research platform: The case of combinatorial chemistry and biology. Scientometrics, 47(2), 303-321.

Mansfield, E. (1991). Academic research and industrial innovation. Research Policy, 20(1), 1-12. https:// doi.org/10.1016/0048-7333(91)90080-A.

Mansfield, E. (1995). Academic research underlying industrial innovations: Sources, characteristics, and financing. The Review of Economics and Statistics, 77(1), 55-65.

Mansfield, E., \& Lee, J. (1996). The modern university: Contributor to industrial innovation and recipient of industrial R\&D support. Research Policy, 25(7), 1047-1058. https://doi.org/10.1016/S0048 -7333(96)00893-1.

McMillan, G. S., Narin, F., \& Deeds, D. L. (2000). An analysis of the critical role of public science in innovation: The case of biotechnology. Research Policy, 29(1), 1-8. https://doi.org/10.1016/S0048 -7333(99)00030-X.

Narin, F., Hamilton, K. S., \& Olivastro, D. (1997). The increasing linkage between U.S. technology and public science. Research Policy, 26, 317-330.

Nikulainen, T., \& Palmberg, C. (2010). Transferring science-based technologies to industry-Does nanotechnology make a difference? Technovation, 30(1), 3-11.

Niosi, J., \& Reid, S. (2007). Biotechnology and nanotechnology: Science-based enabling technologies as windows of opportunity for LDCs? World Development, 35(3), 426-438. https://doi.org/10.1016/j. worlddev.2006.11.004.

Nissen, M. E. (2002). An extended model of knowledge-flow dynamics. Communications of the Association for Information Systems, 8(1), 251-266.

Perez, C., \& Soete, L. (1988). Catching up in technology: Entry barriers and windows of opportunity. In G. Dosi, C. Freeman, R. Nelson, G. Silverberg, \& L. Soete (Eds.), Technical change and economic theory (pp. 458-479). London: Pinter.

Popp, D. (2017). From science to technology: The value of knowledge from different energy research institutions. Research Policy, 46, 1580-1594. https://doi.org/10.3386/w22573.

Sargent, J. F., Jr. (2016). Nanotechnology, a policy primer. Washington, DC: Congressional Research Service.

Schartinger, D., Rammer, C., Fischer, M. M., \& Fröhlich, J. (2002). Knowledge interactions between universities and industry in Austria: Sectoral patterns and determinants. Research Policy, 31, 303-328.

Sorenson, O., \& Fleming, L. (2004). Science and the diffusion of knowledge. Research Policy, 33(10), 1615-1634. https://doi.org/10.1016/j.respol.2004.09.008. 
Stephan, P. (1996). The economics of science. Journal of Economic Literature, 34(3), 1199-1235.

Tornquist, K. M., \& Kallsen, L. A. (1994). Out of the ivory tower: Characteristics of institutions meeting the research needs of industry. The Journal of Higher Education, 65(5), 523-539.

Wang, L., Jacob, J., \& Li, Z. (2019). Exploring the spatial dimensions of nanotechnology development in China: The effects of funding and spillovers. Regional Studies, 53(2), 245-260. https://doi. org/10.1080/00343404.2018.1457216.

Wang, L., \& Li, Z. (2018). Knowledge transfer from science to technology-The case of nano medical device technologies. Frontiers in Research Metrics and Analytics, 3(11), 1-8. https://doi.org/10.3389/ frma.2018.00011.

Wang, L., Notten, A., \& Surpatean, A. (2013). Interdisciplinarity of nano research fields: A keyword mining approach. Scientometrics, 94(3), 877-892. https://doi.org/10.1007/s11192-012-0856-9.

Zucker, L. G., Darby, M. R., Furner, J., Liu, R. C., \& Ma, H. (2007). Minerva unbound: Knowledge stocks, knowledge flows and new knowledge production. Research Policy, 36(6), 850-863. https://doi. org/10.1016/j.respol.2007.02.007.

Publisher's Note Springer Nature remains neutral with regard to jurisdictional claims in published maps and institutional affiliations. 